Article

\title{
Initial steps towards evidenced-based classification for Taekwondo poomsae athletes with intellectual impairments: A pilot study
}

\author{
Ivan Vivaracho ${ }^{1,}{ }^{*}$, Yves Vanlandewijck ${ }^{2}$ and Debbie Van Biesen ${ }^{3}$ \\ Received: $13^{\text {th }}$ November 2017; Accepted: $14^{\text {th }}$ November 2018; Published: $16^{\text {th }}$ January 2019
}

\begin{abstract}
The Paralympic classification process for athletes with intellectual impairments (II) requires sport-specific testing, developed on the basis of evidence about the impact of the underlying impairment on the performance in that sport. The main purpose of this explorative study was to assess the feasibility, reliability and validity of a novel taekwondo poomsae test in a sample of taekwondo poomsae athletes with II. The second purpose was to determine to what extent cognitive aspects of sports intelligence are related to poomsae performance. The final purpose was to understand the relationship between generic working memory and poomsae specific memory. Thirteen poomsae athletes with II ( 8 males and 5 females) performed four cognitive and executive function tests and a novel test, specifically developed for the purpose of this study, to assess taekwondo poomsae performance. Results revealed a significant positive correlation between psychomotor speed and poomsae performance (TPPS), both for the dominant hand $(\mathrm{r}=.766, \mathrm{p}<.05)$ and non-dominant hand $(\mathrm{r}=.658, \mathrm{p}<.05)$. Poomsae specific memory (TPMS) was found to be significantly correlated to mean $(\mathrm{r}=.704, \mathrm{p}=.011)$ and maximum generic working memory $(\mathrm{r}=.655$, $\mathrm{p}=.021$ ). High reliability (TPPS $\mathrm{r}=.982$, ICC $=.97-.99, \mathrm{~d}=.041$; TPMS $\mathrm{r}=.955$, ICC $=.99-.99, \mathrm{~d}=.058$ ) $(\mathrm{p}<.05)$, feasibility and content validity established the taekwondo poomsae test as a potential tool to include in a future evidence-based classification system for taekwondo poomsae athletes with II.
\end{abstract}

Keywords: Paralympics; intellectual disabilities; cognitive abilities; Para-taekwondo; ID.

\section{Introduction}

Athletes with intellectual impairments (II) were re-included in the Paralympic programme in the London 2012 Summer Games, thanks to the development of evidence-based classification systems, as required by the International Paralympic Committee (IPC) classification code. Following this code (IPC, 2007), every sport classification system must indicate how impairment affects the key determinants of performance in a particular sport. Impairment is defined as a problem in body function or structure (Jette, 2006).

Regarding II-classification, each International Sport Federation has to develop their classification system by building on a four-step model to be added into the Paralympic program (Kwon \& Block, 2012). The first two steps are common for every II-sport and the final two steps are sport-specific. Assessment of the first step is done by The International Federation for Athletes with Intellectual Impairments (INAS), while a classification panel appointed by the International Federation for that sport performs the other three steps. At the first step, athletes should meet the eligibility criteria. INAS recognizes the definition of II given by the World Health Organisation and American Association on Intellectual and Developmental Disabilities (AAIDD), which stipulates three conditions that an athlete should demonstrate: Impairment of Intellectual functioning (IQ $\leq 75)$, limitations in adapted behaviour, and the impairment must be evident during the developmental period (from conception to 18 years of age) (AAIDD, 2010). At the second step, sports intelligence of the athlete is evaluated, by performing the Generic Cognitive Test (Van Biesen, Mactavish, McCulloch, Lenaerts, \& Vanlandewijck, 2016). Sports intelligence assessment focuses only on the 
cognitive abilities which are essential in sport, leaving apart other generic cognitive factors that are not relevant in sport situations. At the third stage, athletes are asked to perform a sport-specific test, in which the key determinants of sport performance are assessed. The fourth and last step concerns the observation during competition. The assessment of performance parameters through observation (e.g., overall sport proficiency, physical profile, technical and tactical skills) complements the athlete appraisal.

This pilot study aims to be an initial step towards the development of an evidenced-based classification system for taekwondo poomsae, focusing mainly on third stage of the classification process, i.e. the assessment of key determinants of poomsae performance. Nowadays, no classification system exists, with INAS eligibility criteria the only assessing tool currently being used.

According to the classification code (IPC, 2007), a relationship between II and sports performance needs to be proven. Based on findings of Van Biesen et al. (2016) concerning sports intelligence and its assessing tool (Generic Cognitive Test), associations between cognition and performance could be found across different sports. Table tennis athletes with II showed reduced tactical proficiency when compared to players without II (Van Biesen, 2014). Regarding swimming performance, technical skills are affected by impairment. Swimmers with Down syndrome got different intracyclic velocity variations and lower index of coordination than athletes without II, having affected both gradient and propulsion (Marques-Aleixo et al., 2013). In long distance running events, athletes with II showed difficulties in pacing, more specifically they lacked the ability to maintain a pre-planned submaximal velocity (Van Biesen, Hettinga, McCulloch, \& Vanlandewijck, 2016).

Considering how this complex relationship differs depending on the sport, the second aim of this pilot study was to explore and understand which cognitive abilities are related with taekwondo poomsae performance in athletes with II. These findings would therefore be related with the third stage of the II-classification process.

Taekwondo poomsae is described as a standard defined pattern of defensive and offensive hand and foot techniques, matched with specific body positions (Choi \& Joo, 2015). Previous research concerning poomsae performance in young healthy adults showed a strong positive correlation $(\mathrm{r}=.76, \mathrm{p}<.001)$ between intelligence and taekwondo performance (Mihaela, Gabriela, Catalin, Gabriel, \& Nicolae, 2013). In their study, Mihaela et al. (2013) assessed intelligence using the generic intelligence test Raven Progressive Matrices (Raven, 2000). Taekwondo performance was quantified by analysing the execution of three different techniques. Further investigation is needed to deeply understand which sports intelligence aspects are related to which determinants of poomsae performance, specifically in athletes with II.

To excel in Taekwondo poomsae, athlete's performance is determined by the accomplishment of two main categories during its execution: presentation and accuracy (WTF, 2016). Presentation in determined by concepts such as rhythm, speed, expression of energy and completion of poomsae movements. Accuracy includes the following components: basic stance and practicability of movements, hand and foot techniques, posture, balance and sequence of the poomsae line (WTF, 2016). Moreover, given the fact that each poomsae consists of fixed sequences, it has to be memorized, learned and performed following the poomsae rules and regulations provided by the World Taekwondo Federation (WTF, 2014).

It has been demonstrated that taekwondo poomsae determinants of performance may be affected in individuals with II. When compared to adults without II, adults with II showed reduced balance control (Cabeza-Ruiz et al., 2011; Zur, Ronen, Melzer, \& Carmeli, 2013), lower strength levels, reduced postural balance (Blomqvist, Olsson, Wallin, Wester, \& Rehn, 2013) and lower speed (Hartman, Smith, Westendorp, \& Visscher, 2015). These findings may suggest that an II would lead to poorer taekwondo poomsae performance.

When it comes to learning and memorizing processes during sports practices, working memory plays an important role especially in early stages of training (Furley \& Memmert, 2010). Working memory is defined as the brain capacity to retain information when performing other cognitive processes (Baddeley, 2010). Researches have highlighted the important role of working memory in 
sport situations. During handball and basketball situations, athletes without II showed passing decision making associated with working memory, particularly when several decision options are available (Furley \& Memmert, 2013). A connection between generic working memory (i.e., memory assessed in a non sport-specific way) and taekwondo poomsae specific memory (i.e., the ability to memorize taekwondo specific movement sequences) was found by Pons van Dijk, Huijts and Lodder (2013), who studied the effect of taekwondo training in healthy adults. Their findings revealed that after 15 months of poomsae training, participants showed improvements in generic working memory span. During the training period, participants had to practise and memorize three different poomsaes, demanding memory training for complex motor sequences (taekwondo poomsae specific memory).

On the other hand, the role of working memory in II poomsae performance remains unknown. Due to the fact that individuals with II often present reduced generic memory span (Lanfranchi, Cornoldi, \& Vianello, 2004; Van Biesen, Mactavish, McCulloch et al., 2016), it is crucial to know its association with taekwondo poomsae specific memory. If that relationship exists (generic-sport specific memory), the influence of II on taekwondo poomsae performance will be better understood, being particularly evident during learning and memorizing processes.

This pilot study is the very first study assessing taekwondo poomsae proficiency in athletes with II. Due to the lack of an assessment tool that evaluates key determinants of poomsae performance, the first aim of our pilot study was to evaluate the feasibility, validity and reliability of a novel taekwondo poomsae specific test developed for the purpose of this study. As a first approach to find scientific evidence of the relationship between impairment and sport performance, the second purpose was to determine the relationship between four cognitive abilities of sports intelligence (simple reaction time, complex reaction time, psychomotor speed and working memory) and taekwondo poomsae performance in athletes with II. The third aim was to investigate if the athlete's generic working memory is directly related with their taekwondo poomsae-specific memory.

We hypothesize that the novel taekwondo poomsae test will be a valid, feasible and reliable tool that could be implemented in future classification processes. It is also hypothesized that there may exist a correlation between some cognitive abilities and taekwondo poomsae performance. Moreover, we also assume that a reduced generic working memory span will be related to reduced ability to memorize taekwondo poomsae sequences.

\section{Materials and Methods}

\section{Participants}

The total sample consisted of 13 taekwondo poomsae athletes with II, eight males and five females (age $=26.4$ years \pm 10.7) who participated in the Austrian Poomsae Open 2016 (Vienna, 11-12 June 2016). These participants represent $100 \%$ of the athletes with II taking part in the Austrian Open. They came from seven different countries: Croatia $(n=5)$, Austria $(n=2)$, Italy $(n=2)$, China $(n=1)$, Belgium ( $\mathrm{n}=1)$, Great Britain $(\mathrm{n}=1)$ and Serbia $(\mathrm{n}=1)$.

Inclusion criteria was set as follows: Every male and female athlete participating in the Austrian Poomsae Open 2016 with an intellectual impairment according to INAS eligibility criteria (Impairment of Intellectual functioning (IQ $\leq 75)$, limitations in adapted behaviour, and the impairment must be evident during the developmental period) (AAIDD,2010). As a result, 13 athletes were selected for our pilot study. Six of these athletes were diagnosed with Down Syndrome, the other seven athletes were diagnosed with intellectual impairment, but no specific genetic disorder.

All participants signed an informed consent form. Ethical approval was provided by the Ethics Committee of the KU Leuven (number: S57643). Training volume was reported by the coaches. Male athletes had a training volume (hours accumulated: hours of training per week by 52 weeks by years of taekwondo experience) of 2541.5 hours \pm 2734.7 whereas, female had 1125.8 hours \pm 1928.6. 


\section{Procedure}

The testing process consisted of two parts that were both conducted in a quiet room, free from any distractions. The participant's coach was present during the assessment. The first part was a cognitive assessment, and the second part was a sport-specific taekwondo poomsae test.

\section{Cognitive assessment}

Four computerized tests were performed to assess reaction time (i.e., simple reaction time test, complex reaction time test), memory (i.e., Corsi block tapping task), and psychomotor speed (i.e., Finger Tapping Test). These four tests are part of the Generic Cognitive Test Battery, that is internationally used within the classification process of athletes with II. The Generic Cognitive Test Battery, detailed psychometric features and application information of each subtest is provided by Van Biesen, Mactavish, McCulloch et al. (2016). Scoring details and outcome variables are presented in Table 3.

Participants were sat in front of a touch screen computer, in which the four subtest of the generic cognitive test were presented. Prior to each subtest, practical demonstrations were provided to the participants, until total comprehension of the different subtests was ensured. The whole process of cognitive test assessment took approximately 20 minutes.

\section{Taekwondo Poomsae Test}

Taekwondo poomsae assessment was conducted by performing a novel specific test for athletes with II, developed in collaboration with the Research and Education Committee of the World Taekwondo Federation. The test consisted of replicating in the most accurate way two poomsae sequences. Taekwondo poomsae is described as a defined pattern of defensive and offensive hand and foot techniques, matched with specific body positions. These sequences of movements were not associated to any of the standard poomsaes that every athlete practises during their daily training routines (=non-standard) and were not therefore known or trained at all by any participant.

After a short warm-up, athletes received instructions for the test. First of all, they were invited to watch three times the first poomsae sequence, which was displayed on a laptop (MacBook Air 13). Athletes could observe a professional poomsae athlete performing a non-standard poomsae, which consisted of three strikes and one kick, executed in a linear way. They were asked to pay attention and to memorize it, as a previous step before practice. Having seen the video three times, athletes practised the poomsae three times, guided by a highly experienced taekwondo researcher who was familiar with the poomsae sequences. Once the three observation and practises were finished, it was the athlete's turn now to perform twice that first poomsae as accurately as possible.

For those athletes who were able to perform the first poomsae correctly, the same process was repeated, this time for the second and more complex non-standard poomsae to be executed. In this case, the procedure followed the identical sequence of a warm-up and three successive observations, practises, and poomsae performances. The second pattern included a more dynamic presentation of strikes, blocks, kicks and stances, comprising also a jumping manoeuvre. Both poomsaes were developed following the World Taekwondo Federation referee scoring regulations (WTF, 2014).

\section{Material}

Poomsae assessment was performed on a Tatami Mat $(4 \times 4 \mathrm{~m})$, and recorded from the frontal, left side and right side plane using three iPads (Figure 1). Recording devices were adjusted to ensure full range camera view of the athlete performing different taekwondo patterns. 


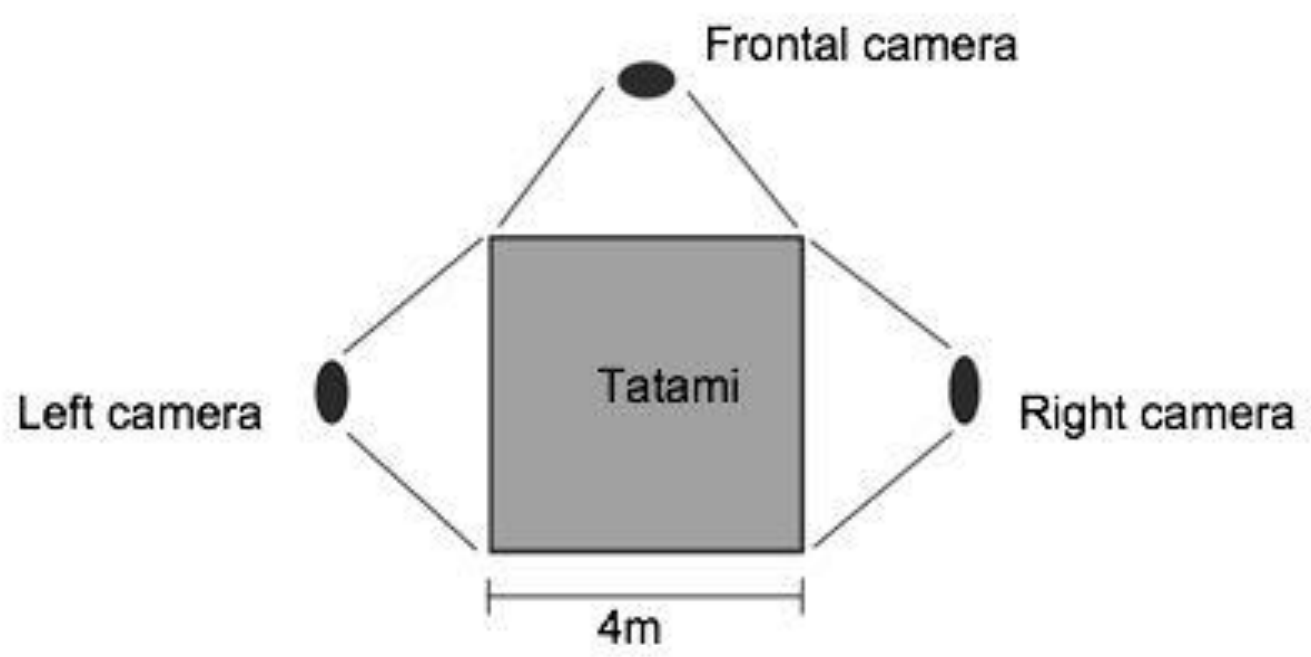

Figure 1: Taekwondo Poomsae Test setup.

\section{Video analysis}

Expert opinion was considered to identify the poomsae determinants with a cognitive load. Accordingly, we created a scoring system based on the para-taekwondo scoring criteria (WTF, 2014) that aimed to assess those relevant determinants of poomsae performance. The poomsae video analysis was evaluated following a scoring sheet by one expert observer. As athletes were asked to execute the poomsae sequences twice, only their best trial was assessed. Video analysis of all the athletes was performed twice by the same observer, with a time interval of two months, to later analyse the intra-rater reliability of the test measurements.

The scoring rubric is divided into two categories: poomsae performance and poomsae memory. Each category will provide a final score. Maximum value for each poomsae sequence performance is 10, while those for poomsae memory are 10 and 20 respectively for the first and second sequence. Athletes were asked to execute the second poomsae pattern if they were able to perform the first one correctly. Therefore, an athlete who performed both sequences will have a higher total score than someone who could not perform the first one.

The scoring rubric will be filled out twice in case an athlete is able to perform the second poomsae pattern. Consequently, results of the $1^{\text {st }}$ poomsae performance will be added to the results of the $2^{\text {nd }}$ poomsae performance, resulting in the total poomsae performance score (TPPS). Results of the $1^{\text {st }}$ poomsae memory will be added to the results of the $2^{\text {nd }}$ poomsae memory, resulting in the total poomsae memory score (TPMS). For those athletes who did not perform the second poomsae, the first poomsae scores was be the same as the total scores.

\section{Poomsae performance}

Eight different subcategories determining poomsae performance were assessed in a scale from 1.25 to 0.05 (perfect to bad). The evaluated subcategories comprised of, stance, hand/foot technique, posture, balance, power/strength, speed/rhythm, expression of energy and attention. Table 1 presents the scoring table for these subcategories. Details information of each subcategory can be found in Appendix A.

\section{Poomsae memory}

Poomsae-specific memory was assessed by the evaluation of four different subcategories: movements corresponding with the poomsae pattern ( 1 point $x$ movement), movements executed in 
the right direction will be counted (1 point $\mathrm{x}$ movement), movements executed with the wrong foot/hand ( 0.5 points $x$ movement) and hesitations ( -0.5 points $x$ movement). Table 2 shows the scoring table for poomsae-specific memory subcategories. Detailed information of each subcategory can be found in Appendix A.

Table 1. Example of the scoring table for poomsae performance.

\begin{tabular}{|c|c|c|c|c|c|c|c|c|}
\hline $\begin{array}{l}\text { Determinant of } \\
\text { performance }\end{array}$ & $\begin{array}{l}\text { Perfect } \\
(1.25) \\
\end{array}$ & $\begin{array}{l}\text { Very } \\
\text { good } \\
(1.05) \\
\end{array}$ & $\begin{array}{l}\text { Good } \\
(0.85) \\
\end{array}$ & $\begin{array}{c}\text { Average } \\
(0.65) \\
\end{array}$ & $\begin{array}{c}\text { Below } \\
\text { average } \\
(0.45)\end{array}$ & $\begin{array}{l}\text { Poor } \\
(0.25)\end{array}$ & $\begin{array}{l}\text { Very } \\
\text { poor } \\
(0.05) \\
\end{array}$ & $\begin{array}{l}\text { Score of the } \\
\text { determinant }\end{array}$ \\
\hline Stance & & & $X$ & & & & & 0.85 \\
\hline Hand/foot techniques & & $x$ & & & & & & 1.05 \\
\hline Posture & & & $x$ & & & & & 0.85 \\
\hline Balance & & & & $x$ & & & & 0.65 \\
\hline Power/strength & & & & & & $x$ & & 0.25 \\
\hline Speed/rhythm & & $x$ & & & & & & 1.05 \\
\hline Expression of energy & & $x$ & & & & & & 1.05 \\
\hline Attention & & & & $X$ & & & & 0.65 \\
\hline $\begin{array}{c}1^{\text {st }} \text { POOMSAE PERFOl } \\
\text { SCORE }\end{array}$ & ANCE & & & & & & & 6.4 \\
\hline
\end{tabular}

Table 2. Example of the scoring table for poomsae memory.

\begin{tabular}{cc}
\hline Determinant of poomsae memory & $\begin{array}{c}\text { Number of } \\
\text { movements }\end{array}$ \\
\hline Movements corresponding with the poomsae pattern & 5 \\
Movements executed in the right direction & 5 \\
Hesitations (-0.5 x movement) & $(-0,5 \times 2)=-1$ \\
Movements executed with the wrong foot/hand $(0.5 \times$ movement $)$ & 0 \\
\hline 15T POOMSAE MEMORY SCORE & 9 \\
\hline
\end{tabular}

\section{Outcome variables}

Nine variables were used for subsequent analysis. Description of all variables can be found in Table 3. Due to variability in taekwondo training volume among the sample of athletes, this variable was also taken into consideration.

\section{Data analysis}

Statistical analysis was performed by using the software IBM SPSS Statistics for Macintosh (Version 23.0) with a level of significance set at $\mathrm{p}<.05$. In order to analyse the intra-rater reliability of the Taekwondo Poomsae Test, spearman rho correlation between the results of the first and second video analysis were calculated, both for poomsae performance and poomsae memory measurements. Reliability analysis was used to calculate Intra-class Correlation Coefficient (ICC). Effect sizes (ES) were calculated as:

$$
\text { Cohen's d= (Mean1-Mean2)/SD }
$$

where

$$
\mathrm{SD}=\sqrt{ }\left[\left(\mathrm{SD}_{1}{ }^{2}+\mathrm{SD}_{2}{ }^{2}\right) / 2\right]
$$


Values were interpreted based on Cohen (1988) who labelled an effect size 'small' if ES $<0.5$, "moderate" if ES between 0.5 and 0.8 , or "large" if ES $\geq 0.8$. Standard Deviations (SD) for both tests were multiplied by

$$
\mathrm{SEM}=\mathrm{SD}^{*} \sqrt{ }(1-\mathrm{ICC})
$$

Coefficient of Variation (expressed and percentage) was calculated as,

$$
\text { Coefficient of Variation }=(\text { Standard Deviation } / \text { Mean }) * 100
$$

Bland \& Altman was used to display the agreement between test and re-test of the taekwondo poomsae tests (TPPS and TPMS). The difference between the first and second test is plotted against the participant's mean (Figure 2). The centre line corresponds to the mean difference between the two tests and the outer lines show the $95 \%$ limits of agreement (average difference \pm 1.96 SD of the difference).

\begin{tabular}{|c|c|c|c|c|}
\hline Outcome variables: & Abbreviation & Definition & Measurement unit & Test \\
\hline Mean of SRT values & SRTmean & $\begin{array}{l}\text { Average response time over } 12 \\
\text { consecutive trials of the SRT test }\end{array}$ & Milliseconds (ms) & SRT \\
\hline Mean of CRT values & CRTmean & $\begin{array}{c}\text { Average response time over } 12 \\
\text { consecutive trials of the CRT } \\
\text { test }\end{array}$ & Milliseconds (ms) & CRT \\
\hline Mean of CMT values & $\mathrm{CMT}_{\text {mean }}$ & Mean of CMT values & Number of blocks & CMT \\
\hline $\begin{array}{c}\text { Maximum CMT values } \\
\text { of each athlete }\end{array}$ & $\mathrm{CMT}_{\max }$ & $\begin{array}{c}\text { Maximum CMT values of each } \\
\text { athlete }\end{array}$ & Number of blocks & CMT \\
\hline $\begin{array}{l}\text { Best results of the } \\
\text { dominant hand }\end{array}$ & DomFT & $\begin{array}{l}\text { Largest number of taps within } \\
10 \text { s, using the dominant hand. }\end{array}$ & Number of taps in $10 \mathrm{~s}$ & FT \\
\hline $\begin{array}{l}\text { Best results of the non- } \\
\text { dominant hand }\end{array}$ & nonDomFT & $\begin{array}{c}\text { Largest number of taps within } \\
\text { 10s, using the non-dominant } \\
\text { hand }\end{array}$ & Number of taps in $10 \mathrm{~s}$ & FT \\
\hline $\begin{array}{c}\text { Total poomsae } \\
\text { performance score of } \\
\text { the TPT }\end{array}$ & TPPS & $\begin{array}{l}\text { Total poomsae performance } \\
\text { score obtained in the TPT }\end{array}$ & Points & TPT \\
\hline $\begin{array}{c}\text { Total poomsae } \\
\text { memory score of the } \\
\text { TPT }\end{array}$ & TPMS & $\begin{array}{c}\text { Total poomsae memory score } \\
\text { obtained in the TPT }\end{array}$ & Points & TPT \\
\hline $\begin{array}{l}\text { Total of training hours } \\
\text { accumulated }\end{array}$ & $\begin{array}{l}\text { Training } \\
\text { Volume }\end{array}$ & $\begin{array}{l}\text { Total of hours accumulated: } \\
\text { hours of training per week by } \\
52 \text { weeks by years of } \\
\text { taekwondo experience }\end{array}$ & Number of hours & - \\
\hline
\end{tabular}

Table 3. Outcome variables obtained for the cognitive subtests and the Taekwondo Poomsae Test.

Note. SRT $=$ Simple Reaction Time test; $\mathbf{C R T}=$ Complex Reaction Time test; $\mathbf{C M T}=$ Corsi Memory Test; FT= Finger-tapping test; TPT= Taekwondo Poomsae Test.

Descriptive information (mean, standard deviation, maximum and minimum values) were calculated for each outcome variable. In order to understand the association between poomsae performance and the different cognitive and executive function variables, Spearman's partial correlations were calculated between poomsae performance (TPPS) and SRT mean, CRTmean, DomFT, nonDomFT, CMT mean and training volume. Partial correlation between variables was controlled by the variable "age". Finally, the association between generic working memory (CMT mean and CMT $\max$ ) and poomsae specific memory (TPMS) was also calculated by performing spearman's partial correlations between the different variables. Correlation between variables was also controlled by the variable "age". 

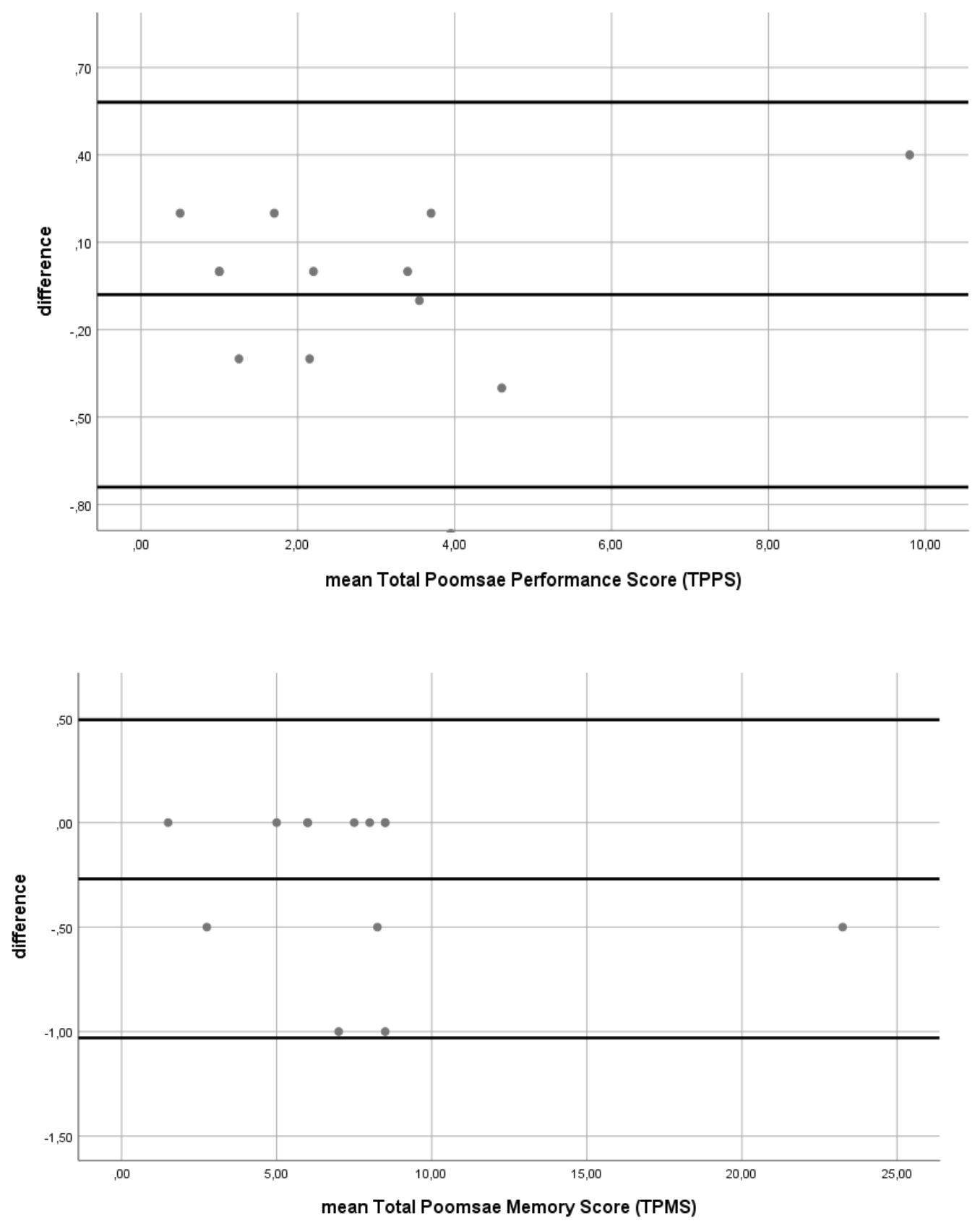

Figure 2. Bland \& Altman Plot displaying the agreement between test and re-test of the Taekwondo Poomsae Tests (TPPS and TPMS).

\section{Results}

Results concerning test-retest reliability (intra-rater) showed high correlation at $\mathrm{p}<.01$, both for poomsae performance $(\mathrm{r}=.982)$ and poomsae memory assessments $(\mathrm{r}=.955)$. Small effect size was found for TPPS ( $\mathrm{d}=.041$ ) while moderate effect size for TPMS was calculated ( $\mathrm{d}=.058)$. Moreover, high intra-class correlation coefficient and low standard error of measurement have been reported as shown in Table 4, for both parts of the taekwondo poomsae test. Descriptive information of the athletes concerning the different outcome variables is presented in Table 5.

Spearman's partial correlations between TPPS and cognitive variables are shown in Table 6 . Results of the finger tapping test appear to be significant both for the dominant hand $(r=.766, p<.05)$ and non-dominant hand $(\mathrm{r}=.658, \mathrm{p}<.05)$. No significant correlations were found between the other cognitive abilities and the poomsae performance score. Likewise, training volume did not appear to have a significant relation with poomsae performance. 
Spearman's partial correlations between TPMS and the associated variables (Corsi Memory Test results and training volume) were calculated. Significant correlations were found between poomsae specific memory (TPMS) and generic working memory: $\mathrm{CMT}_{\text {mean }}(\mathrm{r}=.704, \mathrm{p}=.011)$ and $\mathrm{CMT}_{\max }(\mathrm{r}=.655$, $\mathrm{p}=.021)$ (Table 7).

Table 4. Test-retest reliability.

\begin{tabular}{|c|c|c|c|c|c|c|c|c|c|}
\hline \multirow{2}{*}{ Measure } & \multicolumn{3}{|c|}{ Test 1} & \multicolumn{3}{|c|}{ Test 2} & \multirow{2}{*}{ Cohen's d } & \multirow{2}{*}{$\begin{array}{c}\text { ICC } \\
(95 \% \text { CI })\end{array}$} & \multirow{2}{*}{ SEM } \\
\hline & Mean & SD & $\mathrm{CV}$ & Mean & SD & $\mathrm{CV}$ & & & \\
\hline $\begin{array}{l}\text { TPPS (points, } \\
\max 20)\end{array}$ & 2.9 & 2.5 & $86,2 \%$ & 3 & 2.4 & $80 \%$ & .041 & $.99(.97-.99)$ & .25 \\
\hline $\begin{array}{l}\text { TPMS (points, } \\
\max 30 \text { ) }\end{array}$ & 7.6 & 5.1 & $67,1 \%$ & 7.9 & 5.2 & $65,8 \%$ & .058 & $.99(.99-.99)$ & .51 \\
\hline
\end{tabular}

Note. TPPS= Total Poomsae Performance Score of the Taekwondo Poomsae Test; TPMS= Total Poomsae Memory Score of the Taekwondo Poomsae Test $\mathbf{C V}=$ Coefficient of Variation; ICC= Intra-class Correlation Coefficient; $\mathbf{C I}=$ Confidence Interval; SEM= Standard Error of Measurement

Table 5. Descriptive information of the outcome variables.

\begin{tabular}{ccccc}
\hline Measure & Mean & SD & Min & Max \\
\hline Age (years) & 26.4 & 10.7 & 10.1 & 48.9 \\
Training volume (hours accumulated) & 1997 & 2473.1 & 78 & 7488 \\
SRT mean (ms) & 923 & 309.8 & 493.2 & 1461.1 \\
CRT mean (ms) & 1171.9 & 224 & 719 & 1616.1 \\
CMT mean $_{\text {(sequence length) }}$ & 2.8 & 1.1 & 0.9 & 3.9 \\
CMT $_{\max }$ (sequence length) & 3.2 & 1.3 & 1 & 5 \\
DomFT (number of taps) & 56.4 & 8.5 & 41 & 70 \\
nonDomFT (number of taps) & 55 & 11.1 & 34 & 71 \\
TPPS (points, max 20) & 2.95 & 2.5 & 0.6 & 10 \\
TPMS (points, max 30) & 7.6 & 5.1 & 1.5 & 23 \\
\hline
\end{tabular}

Note. SRT $_{\text {mean }}=$ Mean of Simple Reaction Time test values; $\mathbf{C R T}_{\text {mean }}=$ Mean of Complex Reaction Time test values; $\mathbf{C M T}_{\text {mean }}=$ Mean of Corsi Memory Test values; $\mathbf{C M T}_{\max }=$ Maximum values of the Corsi Memory Test; DomFT= Best result of Finger-tapping test for the dominant hand; nonDomFT= Best result of Finger-tapping test for the non-dominant hand; TPPS= Total Poomsae Performance Score of the Taekwondo Poomsae Test; TPMS= Total Poomsae Memory Score of the Taekwondo Poomsae Test; Min= minimum value; Max= maximum value.

Table 6. Spearman partial correlation between the cognitive and executive function variables and the total poomsae performance score, when controlling for variable "age".

\begin{tabular}{lccccccc}
\hline \multicolumn{2}{c}{ Correlations } & SRT mean & CRT mean & DomFT & nonDomFT & CMT mean $^{2}$ & $\begin{array}{c}\text { Training } \\
\text { Volume }\end{array}$ \\
\hline \multirow{2}{*}{ TPPS } & R value & -.257 & -.353 & $.766^{*}$ & $.658^{*}$ & .558 & 0.292 \\
& Sig. (2-tailed) & .420 & .261 & .004 & .020 & .059 & 0.357 \\
\hline
\end{tabular}

Note. TPPS= Total Poomsae Performance Score of the Taekwondo Poomsae Test; SRT mean= Mean of Simple Reaction Time test values; $\mathbf{C R T}_{\text {mean }}=$ Mean of Complex Reaction Time test values; DomFT= Best result of Fingertapping test for the dominant hand; nonDomFT= Best result of Finger-tapping test for the non-dominant hand; $\mathbf{C M T}_{\text {mean }}=$ Mean of Corsi Memory Test values. ${ }^{*}$ p. $<.05$. 
Table 7. Spearman partial correlation between the cognitive and executive function variables and the total poomsae memory score, when controlling for variable "age".

\begin{tabular}{ccccc}
\hline \multicolumn{2}{c}{ Correlations } & CMT $_{\text {mean }}$ & CMT $_{\max }$ & $\begin{array}{c}\text { Training } \\
\text { Volume }\end{array}$ \\
\hline \multirow{2}{*}{ TPMS } & R value & $.704^{*}$ & $.655^{*}$ & .239 \\
& Sig. (2-tailed) & .011 & .021 & .454
\end{tabular}

Note . TPMS $=$ Total Poomsae Memory Score of the Taekwondo Poomsae Test; $\mathbf{C M T}_{\text {mean }}=$ Mean of Corsi Memory Test values; $\mathbf{C M T}_{\max }=$ Maximum values of the Corsi Memory Test. ${ }^{*}$ p. $<.05$.

\section{Discussion}

The present pilot study was a first step towards the development of an evidence-based classification system for taekwondo poomsae in athletes with II. For the purpose of this study, a taekwondo specific test was developed, to assess key determinants of poomsae performance. Our first aim was to analyse the feasibility, reliability and validity of this novel taekwondo poomsae test Moreover, we investigated the relationship between poomsae performance on one hand, and reaction time, psychomotor speed and memory span on the other hand. The final objective was to explore if memory span, i.e., the ability to memorize abstract sequences of blocks, was related to the ability to memorize taekwondo-specific movement sequences.

At first, we hypothesized that the taekwondo poomsae test would be a feasible, reliable and valid tool to assess taekwondo determinants of performance. Our experience in this pilot study confirmed that the taekwondo poomsae test is a very feasible tool. Every athlete was able to understand the instructions and perform the test in about 20 minutes, showing very high potential to fit into a future II-classification process. However, differences in understanding the test by some of the athletes could make it hard to be standardized for this population. Therefore, being flexible is important to ensure the best performance of each athlete.

Due to the lack of a gold-standard procedure, content validity was ensured by highly considering expert opinion. Besides, Para-Taekwondo scoring criteria (WTF, 2014) was used to identify the poomsae determinants of performance. As a result, the very first tool that assesses taekwondo poomsae performance and taekwondo poomsae specific memory has been created.

Excellent intra-rater reliability of the taekwondo poomsae test has been proved, showing high correlation and intra-class correlation coefficients. However, there is an external variable that might affect negatively the reliability of our test. Although the time needed to complete the test was short, poomsae performance and poomsae memory scores could be influenced by a lack of motivation, especially if maximum performance is required (Chia, Lee, \& Teo-Koh, 2002). To minimize motivation effect, we tested the best international athletes with II, so high motivation and willingness were assumed. They were also asked to perform their best, receiving positive support from researchers and coaches.

In general, athletes showed huge variance in performance of the different outcome variables (Table 5), both for the cognitive and the sport performance variables. Comparable achievement variations were also reported in other studies with athletes with II, especially when compared with athletes without II (Cisic, 2016; Pinilla, Pérez-Tejero, Van Biesen, \& Vanlandewijck, 2015; Van Biesen, Mactavish, \& Vanlandewijck, 2014). Differences in performance between athletes could also be caused by differences in training volume and age. Differences in training volume (hours accumulated) between males and females were not significant, but there was a big difference between the least (78h) and the most experienced athlete (7488h).

Our second hypothesis was that a correlation between some cognitive abilities and taekwondo poomsae performance may exist. Our results confirmed this hypothesis, since psychomotor speed (DomFT and nonDomFT) was found to be significantly correlated with taekwondo poomsae performance. This might be due to the fact that psychomotor speed is the only ability that is mostly independent from the cognitive control (McGrew, 2009). Similar relationship was observed when the 
relationship between psychomotor speed and rowing performance was studied (Nederhof, Visscher, \& Lemmink, 2008). As for simple and complex reaction times, no significant correlations were observed. This disagrees with previous studies in table tennis (Van Biesen, Kerremans, Mactavish, \& Vanlandewijck, 2016), in which simple reaction time was found as a predictor of performance in elite athletes with II. This highlights one more time the complexity of human cognition, and how its influence on sports performance differs depending on the sport. It also demonstrates the different cognitive abilities that lead to success in each particular sport. Likewise, Mihaela et al. (2013) found a significant correlation between IQ (generic intelligence) and taekwondo performance. The discrepancy with our results could be due to the fact that some cognitive abilities of sports intelligence were not studied in our project.

Significant correlation was found between poomsae specific memory (TPMS) and generic working memory: CMTmean and CMTmax This finding supports the investigation of Pons van Dijk et al. (2013) in able bodied adults, who revealed improvements in generic working memory through taekwondo poomsae training. Our results also indicate that, as hypothesized, a reduced generic working memory span is significantly related to reduced ability to memorize taekwondo poomsae sequences in athletes with II.

When looking at the relationship between training volume and sport-specific performance, no significant correlation was found. Similar findings were reported by Allard, Graham and Paarsalu (1980) who looked at basketball players. Expert players were better than non-players in recalling structure slides, which represented an offensive play. That superior performance was not observed when recalling an unstructured game. These findings agree with ours, as athletes with II did not show higher ability to recall the non-standard poomsaes regardless of their training volume.

In general, lack of significance in the results may also be caused by the limitations of our study. We need to take into account that taekwondo poomsae competition for athletes with II is a very recent II sport discipline (2014). We tested all the athletes taking part in the Austrian Poomsae Open 2016, an event that gathered most of the top level athletes at that time. Likewise, taekwondo poomsae test was developed for this pilot study, as well as its scoring sheet to assess poomsae performance and poomsae memory. They are completely new, and their inter-rater reliability needs to be proven. Besides, there is not any well-established test to compare our results with, in order to improve concurrent validity.

The recent emergence of this taekwondo discipline for athletes with II, is reflected in the high disparity concerning their training experience. Many athletes participating in this pilot study were not enough experienced and well-trained. Big standard deviations regarding training experience (males: 2541.5 hours \pm 2734.7 , females: 1125.8 hours \pm 1928.6 ) indicated that some athletes were quite novice and probably not very skilled. Moreover, six athletes had Down Syndrome, which is not represented by the top athletes of INAS competitions. This fact can lead to poorer results in both taekwondo performance or cognitive abilities. Height and weight of the sample must be taken into consideration in future studies, as poor poomsae performance can also be caused by overweight, which may have been the case for some of the athletes participating. Therefore, results have to be interpreted cautiously and cannot be generalised. Moreover, the sample was small, and also showed varying age. Another limitation of our study was the fact that only three out of eight subtests of sports intelligence were applied. Deeper understanding needs to be generated to ensure full coverage of those cognitive variables that are necessary during sport practises.

\section{Conclusions}

This pilot study is the first to relate cognitive abilities of sports intelligence and taekwondo poomsae performance in athletes with II. Therefore, it can establish the basis for the upcoming development of an evidence-based classification system for taekwondo athletes with intellectual impairments.

The Taekwondo Poomsae Test was found as valid, feasible and reliable for this small sample size, and further application of this test needs to be done in a larger and experienced sample. 
Nevertheless, the obtained results suggest that it has the potential to be considered as sport specific test for a future scientific-based sport specific classification system for taekwondo athletes with II.

The relationship between some variables of sports intelligence and sport taekwondo poomsae performance has been revealed. Results showed psychomotor speed to be significantly related with poomsae performance. No significant findings were obtained for simple reaction time, complex reaction time and working memory values when being correlated with taekwondo poomsae performance.

On the other hand, generic working memory was significantly related to poomsae specific memory in adults with II. Further investigation is necessary to cover the full range of cognitive abilities of sports intelligence, as well as to ensure a bigger and experienced matched sample.

\section{Perspective}

Upcoming investigations do need to be performed in a larger sample that is less variable in training volume, taekwondo experience, and hours of training accumulated. Accordingly, stronger conclusions could be obtained by emphasizing the relationship between cognitive factors and poomsae performance, and by excluding training variables.

In spite of the limitations described, our results suggest that this approach has good potential to be a basis for future investigations in II taekwondo poomsae. For instance, one potential application of this taekwondo poomsae test could be the analysis of comparisons between athletes with and without II. Furthermore, feasibility, content validity and reliability of the test and the scoring systems was high, and clear instructions were provided to facilitate its future execution by other authors. They are novel tools that have the potential to be considered as sport specific tests for a future evidencebased sport-specific classification system for taekwondo athletes with II.

Author Affiliations:

1 KU Leuven, ivan.vivaracho@gmail.com

2 KU Leuven, debbie.vanbiesen@kuleuven.be

3 KU Leuven, yves.vanlandewijck@kuleuven.be

* Correspondence: ivan.vivaracho@gmail.com, Tel.: +32.16.37.65.12

\section{Author Contributions:}

IV: Conceptualizing and drafting the article, revising it critically for important intellectual content, final approval of the version to be published, and accountability for all aspects of the work. YV: Conceptualizing and revising the study critically for important intellectual content, final approval of the version to be published, and accountability for all aspects of the work DV: Conceptualizing and revising the study critically for important intellectual content, final approval of the version to be published, accountability for all aspects of the work, and supervision of the research project.

Funding: This research received no external funding.

Acknowledgments: The authors thank the WTF (World Taekwondo Federation) and their researchers Gabriel P. Fife, David M. O'Sullivan and Olof Hansson for their support to conduct this study and for their valuable input developing the sport-specific test.

Conflicts of Interest: The authors declare no conflict of interest

\section{Appendix A: Detailed information of Poomsae performance and Poomsae memory sub- categories.}

\section{Poomsae Performance:}

- Stance: Technical performance of the different poomsae positions presented in both poomsaes.

- Hand/foot techniques: Technical performance of different poomsae movements (punches and kicks) presented in both poomsaes. Each hand or foot technique is determined by aspects such as specific limb trajectory, and hand or foot position at the end of the movement. 
- Posture: Stances and hand/foot techniques should be executed with correct positioning of feet and hands as well as proper body alignment and with the athlete looking in the right direction.

- Balance: Absolute control of the body movements, without wobbling or shuffling.

- Power/strength: Strongest power shown at the most critical moment of the movement through speed and softness. Actions must be fluent and powerful, showing their maximum strength when the punch, kick or block requires its maximal tension.

- Speed/rhythm: Appropriate connection between actions and variations in speed.

- Expression of energy: Performance aiming to demonstrate concentration, sharpness, courage and believing the real application of the appropriate action.

- Attention: Attention and concentration before, during and after the execution of the pattern.

\section{Poomsae Memory:}

- Movements corresponding with the poomsae pattern: Movements performed by the athlete must be conformed with its original poomsae pattern and have to be executed with the same hand/foot as presented in the video. The number of total movements performed correctly is written in the scoring sheet.

- Movements executed in the right direction: Movements might not correspond entirely to the original sequence, but are executed in the right direction. The number of total movements performed in the correct direction is written in the scoring sheet.

- Movements executed with the wrong foot/hand ( $-0.5 \times$ movement): Movements seem to be memorized and can be executed by the athlete, but are performed with the opposite hand than indicated.

- Hesitations (-0.5 x movement): Any slight pause disrupting the flow of the execution when wavering over the next move. Any hesitation observed is multiplied by -0.5 , being detrimental to the poomsae memory score.

\section{References}

American Association on Intellectual and Developmental Disabilities (AAIDD). (2010). Intellectual disability, definition, classification and systems of support. (11th ed.). Washington, DC: AAIDD.

Allard, F., Graham, S., \& Paarsalu, M. L. (1980). Perception in sport: Basketball. Journal of Sport Psychology, 2, 1421. Doi: $10.1123 /$ jsp.2.1.14

Baddeley, A. (2010). Working memory. Current Biology, 20(4), 136-140. doi:10.1016/j.cub.2009.12.014

Blomqvist, S., Olsson, J., Wallin, L., Wester, A., \& Rehn, B. (2013). Adolescents with intellectual disability have reduced postural balance and muscle performance in trunk and lower limbs compared to peers without intellectual disability. Research in Developmental Disabilities, 34(1), 198-206. doi:10.1016/j.ridd.2012.07.008

Cabeza-Ruiz, R., García-Massó, X., Centeno-Prada, R. A., Beas-Jiménez, J. D., Colado, J. C., \& González, L. M. (2011). Time and frequency analysis of the static balance in young adults with Down syndrome. Gait $\mathcal{E}$ Posture, 33(1), 23-28. doi:10.1016/j.gaitpost.2010.09.014

Chia, Y. H. M., Lee, K. S., \& Teo-Koh, S. M. (2002). High intensity cycling performances of boys with and without intellectual disability. Journal of Intellectual and Developmental Disability, 27(3), 191-200. doi:10.1080/1366825021000008611

Choi, C.-H., \& Joo, H.-J. (2015). Motion recognition technology based remote Taekwondo Poomsae evaluation system. Multimed Tools Appl, 75(21), 13135-13148. doi:10.1007/s11042-015-2901-1

Cisic, T. (2016). Long jump kinematic analysis of athletes with and without intellectual impairment: competition observation and sport specific test. Leuven : KU Leuven. Faculteit Bewegings- en Revalidatiewetenschappen, Leuven.

Cohen, J. (1988). Statistical power analysis for the behavioral sciences (2nd ed.). Hillsdale, NJ: Lawrence Earlbaum Associates.

Furley, P., \& Memmert, D. (2010). The role of working memory in sport. International Review of Sport and Exercise Psychology, 3(2), 171-194. doi:10.1080/1750984X.2010.526238

Furley, P., \& Memmert, D. (2013). Whom should I pass to? The more options the more attentional guidance from working memory. Plos one, 8(5), e62278. doi:10.1371/journal.pone.0062278 
Hartman, E., Smith, J., Westendorp, M., \& Visscher, C. (2015). Development of physical fitness in children with intellectual disabilities. Journal of intellectual disability research : 59(5), 439. doi:10.1111/jir.12142

International Paralympic Committee. (2007). IPC classification code and international standards. [PDF document]. Retrieved from: https://www.paralympic.org/sites/default/files/document/12020108432 9386_2008_2_Classification_Code6_1.pdf

Jette, A. (2006). Toward a common language for function, disability, and health. Physical Therapy, 86(5), 726-734. doi:10.1093/ptj/86.5.726

Kwon, E., \& Block, M. E. (2012). Athletes with intellectual disabilities and the Paralympics. Palaestra, $26(3), 25$.

Lanfranchi, S., Cornoldi, C., \& Vianello, R. (2004). Verbal and visuospatial working memory deficits in children with down syndrome. American Journal on Mental Retardation, 109(6), 456-466. doi:10.1352/08958017(2004)109\&lt;456:VAVWMD\&gt;2.0.CO;2

Marques- Aleixo, I., Querido, A., Figueiredo, P., Vilas- Boas, J. P., Corredeira, R., Daly, D., \& Fernandes, R. J. (2013). Intracyclic velocity variation and arm coordination assessment in swimmers with Down syndrome. Adapted physical activity quarterly : 30(1), 70.

McGrew, K. S. (2009). CHC theory and the human cognitive abilities project: Standing on the shoulders of the giants of psychometric intelligence research. Intelligence, 37, 1-10.

Mihaela, P., Gabriela, G., Catalin, P., Gabriel, P., \& Nicolae, E. (2013). Relationship between general intelligence and motor skills learning specific to combat sports. Procedia - Social and Behavioral Sciences, 84, 728-732. doi:10.1016/j.sbspro.2013.06.635

Nederhof, E., Visscher, C., \& Lemmink, K. (2008). Psychomotor speed is related to perceived performance in rowers. European Journal of Sport Science, 8(5), 259-265. doi:10.1080/17461390802195678

Pinilla, J., Pérez-Tejero, J., Van Biesen, D., \& Vanlandewijck, Y. C. (2015). Performance variability in basketball players with intellectual impairment: Ankara World Championships 2013 analysis. Revista de psicología del deporte, 24(3), 77-83.

Pons van Dijk, G., Huijts, M., \& Lodder, J. (2013). Cognition improvement in Taekwondo novices over forty. Results from the SEKWONDO Study. Frontiers in Aging Neuroscience, 5, 74. doi:10.3389/fnagi.2013.00074

Raven, J. C., \& Court, J. H. (2000). Standard progressive matrices. London, England: Psychology Press.

Van Biesen, D. (2014). The role of intelligence in table-tennis specific performance of athletes with intellectual disabilities (Unpublished doctoral dissertation). KU Leuven, Leuven, Belgium.

Van Biesen, D., Hettinga, F., McCulloch, K., \& Vanlandewijck, Y. (2016). Pacing ability in elite runners with intellectual impairment. Medicine $\mathcal{E}$ Science in Sports \& Exercise. doi:10.1249/MSS.0000000000001115

Van Biesen, D., Kerremans, J., Mactavish, J., \& Vanlandewijck, Y. (2016). Cognitive predictors of performance in well-trained table tennis players with intellectual disability. Adapted Physical Activity Quarterly, 33(4), 324-337. doi: 10.1123/APAQ.2015-0122

Van Biesen, D., Mactavish, J., McCulloch, K., Lenaerts, L., \& Vanlandewijck, Y. C. (2016). Cognitive profile of young well- trained athletes with intellectual disabilities. Research in Developmental Disabilities, 53-54, 377390. doi:10.1016/j.ridd.2016.03.004

Van Biesen, D., Mactavish, J. J., \& Vanlandewijck, Y. (2014). Comparing technical proficiency of elite table tennis players with intellectual disability: simulation testing versus game play. Perceptual and Motor Skills, 118(2), 608-621.

World Taekwondo Federation. (WTF). (2016) Para-taekwondo and deaf-taekwondo. Classification Rules \& Regulations. [PDF document]. Retrieved from: http://www.fespt.com.br/img_impressos/wtf_parataekwondo_and_deaf-taekwondo_classificaiton_rules_and_regulations.pdf

World Taekwondo Federation (WTF). (2014) Para-taekwondo poomsae scoring criteria. [PDF document]. Retrieved from: http://www.worldtaekwondofederation.net/wp-content/uploads/2015/11/WTF_ParaTaekwondo_Poomsae_Socring_Criteria-1.pdf

Zur, O., Ronen, A., Melzer, I., \& Carmeli, E. (2013). Vestibulo- ocular response and balance control in children and young adults with mild-to-moderate intellectual and developmental disability: a pilot study. Research in Developmental Disabilities: A Multidisciplinary Journal, 34(6), 1951-1957. doi:10.1016/j.ridd.2013.03.007

(C) 2018 by the authors. Submitted for possible open access publication under the terms and conditions of the Creative Commons Attribution (CC BY) license (http://creativecommons.org/licenses/by/4.0/). 